\title{
O exercício da liderança e seus desafios na prática do enfermeiro
}

The exercise of the leadership and its challenges in the practice of nursing

El ejercicio del liderazgo y sus desafíos en la práctica del enfermeiro

Siméia Dias da Costa ${ }^{1}$; Patrick Leonardo Nogueira da Silva ${ }^{2}$; Renata Patrícia Fonseca Gonçalves ${ }^{3}$; Lucas Mendes Soares ${ }^{4}$; Wilson Aguiar Filho ${ }^{5}$; Simone Guimarães Teixeira Souto ${ }^{6}$

\section{Resumo}

Liderança é uma habilidade possível de ser adquirida por profissionais que almejam uma posição de destaque no mercado de trabalho contemporâneo, constituindo uma ferramenta indispensável na administração de pessoal, sendo capaz de influenciar a conduta dos indivíduos. O enfermeiro, no exercício da sua profissão, necessita ter uma postura de líder. Objetivou-se identificar os desafios do exercício da liderança na prática do enfermeiro. Trata-se de uma revisão integrativa da literatura referente aos desafios encontrados pelos enfermeiros no exercício da liderança. Foram incluídos periódicos nacionais, disponíveis nas bases de dados BDENF e LILACS, no período de 2000 a 2012. Encontrou-se 477 publicações. A amostra final do estudo foi constituída de 11 dessas publicações, seguindo os critérios de inclusão, sendo considerados os artigos em português disponíveis na íntegra. Foram obtidas quatro categorias temáticas de estudo: Os desafios na prática da liderança no dia a dia do trabalho dos enfermeiros; Compreensão do profissional enfermeiro sobre liderança; Habilidades essenciais para o exercício da liderança e o ensino da liderança na graduação de enfermagem. Os resultados evidenciaram que os enfermeiros encontram-se despreparados para exercerem a função de líder, sendo que essa deficiência coexiste com a falta de conhecimento adequado sobre o termo liderança. Verificou-se ainda a insatisfação desses profissionais quanto ao ensino na graduação sobre liderança, principalmente em relação à prática.

Descritores: Liderança; Equipe de Enfermagem; Recursos Humanos de Enfermagem.

\footnotetext{
${ }^{1}$ Enfermeira pela Universidade Estadual de Montes Claros (UNIMONTES). Avenida Doutor Ruy Braga, s/n, Vila Mauricéia, Montes Claros, MG, Brasil. CEP: 39.401-089. E-mail: simonegts28@yahoo.com.br

${ }^{2}$ Mestrando em Saúde, Sociedade e Ambiente (Área de Concentração em Interdisciplinar e Linha de Pesquisa em Promoção da Saúde, Prevenção e Controle de Doenças) pela Universidade Federal dos Vales do Jequitinhonha e Mucuri (UFVJM). Professor da Escola Técnica de Saúde do Centro de Educação Profissional e Tecnológica. Rua Coronel Celestino, nº 65, Centro, Montes Claros, MG, Brasil. CEP: 39.400-014. E-mail: patrick_mocesp70@ hotmail.com

${ }^{3}$ Doutoranda em Enfermagem (Área de Concentração em Saúde Coletiva e Linha de Pesquisa em Promoção da Saúde, Prevenção e Controle de Agravos) pela Universidade Federal de Minas Gerais (UFMG). Professora e Coordenadora Didática do curso de Enfermagem da Universidade Estadual de Montes Claros (UNIMONTES). Avenida Doutor Ruy Braga, s/n, Vila Mauricéia, Montes Claros, MG, Brasil. CEP: 39.401-089. E-mail: renatapfonseca@yahoo.com.br

${ }^{4}$ Mestre em Nutrição e Saúde (Linha de Pesquisa em Saúde Pública e Área de Concentração em Nutrição e Saúde) pela Universidade Federal de Minas Gerais (UFMG). Enfermeiro, Coordenador do Hospital Universitário de Medicina Veterinária das Faculdades Unidas do Norte de Minas (HUVET/FUNORTE). Avenida Osmani Barbosa, nº 1647, JK, Montes Claros, MG, Brasil. CEP: 39.404-006. E-mail: lucasmoc@msn.com

${ }^{5}$ Mestre em Saúde Pública (Área de Concentração em Política, Planejamento, Gestão e Práticas em Saúde e Linha de Pesquisa em Saúde Coletiva) pela Escola Nacional de Saúde Pública Sérgio Arouca (ENSP). Servidor público da Fundação Oswaldo Cruz (FIOCRUZ). Rua Leopoldo Bulhões, n 1.480, $7^{\circ}$ Andar, Sala 705, Manguinhos, Rio de Janeiro, RJ, Brasil. CEP: 21.041-210. E-mail: aguiar.wilson@gmail.com

${ }^{6}$ Mestre em Enfermagem na Saúde do Adulto (Área de Concentração em Saúde Coletiva e Linha de Pesquisa em Cuidado em Enfermagem e Saúde Coletiva) pela Universidade Federal de São Paulo (UNIFESP). Professora do Departamento de Enfermagem da Universidade Estadual de Montes Claros (UNIMONTES). Avenida Doutor Ruy Braga, s/n, Vila Mauricéia, Montes Claros, MG, Brasil. CEP: 39.401-089. E-mail: simonegts28@yahoo.com.br
} 


\section{Abstract}

Leadership is a skill can be acquired by professionals who target a prominent position in the contemporary labor market and is an indispensable tool in personnel management, being able to influence the conduct of individuals. The nurse, in the exercise of their profession, need to have a leading position. This study aimed to identify the challenges of exercising leadership in nursing practice. This is a integrative review of literature related to the challenges faced by nurses to exercise leadership. National journals available were included in the databases LILACS and BDENF in the period 2000-2012. Was found 477 publications. The final study sample consisted of 11 such publications; the following inclusion criteria were considered articles in Portuguese available in full. Were obtained four thematic categories of study: Challenges in the practice of leadership in the daily work of nurses; Understanding of the professional nurse leadership; Essential skills to exercise leadership and teaching of leadership in nursing degree. The results showed that nurses are unprepared to play the role of leader, and this deficiency coexists with the lack of adequate knowledge about the term leadership. There was also dissatisfaction of these professionals to the college teaching about leadership, especially in relation to practice.

Key-words: Leadership; Nursing Team; Human Resources in Nursing.

\section{Resumen}

El liderazgo es una habilidad puede ser adquirida por los profesionales que se dirigen a una posición destacada en el mercado de trabajo actual y es una herramienta indispensable en la gestión del personal, ser capaz de influir en la conducta de los individuos. La enfermera, en el ejercicio de su profesión, necesita tener una posición de liderazgo. Este estudio tuvo como objetivo identificar los retos de ejercer el liderazgo en la práctica de enfermería. Este es una revisión integradora de la literatura con respecto a los desafíos que enfrentan las enfermeras en el ejercicio del liderazgo. Se incluyeron revistas nacionales disponibles en bases de datos LILACS y BDENF, en el período de 2000 a 2012. Se encontró 477 publicaciones. La muestra final consistió en 11 de estas publicaciones, siguiendo los criterios de inclusión y se consideran los artículos en portugués disponibles en su totalidad. Se resultó en cuatro categorías temáticas de estudio: Retos en la práctica de liderazgo en el trabajo diario de las enfermeras; La comprensión de liderazgo profesional de la enfermería; Las capacidades esenciales para el ejercicio del liderazgo y la enseñanza de liderazgo en el grado de enfermería. Los resultados mostraron que las enfermeras están preparadas para ejercer el papel de líder, y esta deficiencia coexiste con la falta de conocimiento adecuado sobre el término liderazgo. También había insatisfacción de estos profesionales para la enseñanza de grado de liderazgo, especialmente en relación con la práctica.

Palabras-claves: Liderazgo; Grupo de Enfermería; Personal de Enfermería.

\section{Introdução}

Liderança tem sido um tema bastante abordado no âmbito da administração. É uma habilidade possível de ser adquirida por profissionais que almejam uma posição de destaque no mercado de trabalho contemporâneo, constituindo uma ferramenta indispensável na administração de pessoal, sendo capaz de influenciar a conduta dos indivíduos. O enfermeiro, no exercício da sua profissão, necessita ter uma postura de líder. Na Atenção Básica ou nas instituições hospitalares esse profissional lida com pessoas que constituem a equipe de enfermagem, cujo objetivo é assistir 
ISSN 2179-6750

o paciente garantindo-lhe uma assistência holística e eficaz ${ }^{1}$.

Assumir o cuidado é ter a responsabilidade de unir especialidades, moldando um trabalho em equipe que tenha como alvo o sujeito carente da assistência, visando-o em todas as suas dimensões ${ }^{2}$. A forma de coordenar uma equipe foi sofrendo mudanças. A figura autoritária da chefia passou a priorizar o diálogo, inserindo os subordinados nas decisões e dando-lhes a oportunidade de opinar. A liderança passou a ser compreendida como um evento de ação grupal no qual é necessário unir esforços para alcançar o objetivo comum.

No início do século XX, quando o tema liderança começou a ser estudado, o seu conceito era relatado como uma característica nata, sendo que algumas pessoas nasciam para liderarem e outras que não possuíam tal habilidade seriam lideradas. Considera-se hoje que a capacidade de liderar pode ser construída e aprimorada ${ }^{3}$. O indivíduo que exerce a liderança precisa ser capaz de promover mudanças e compreender que os membros de sua equipe devem ser colaboradores ativos nesses processos mutacionais. Não devem, portanto, considerá-los seres subordinados e passíveis de serem controlados o tempo todo ${ }^{4}$.

Os enfermeiros devem distribuir poder aos demais profissionais de enfermagem ${ }^{5}$. Os autores ressaltam que o trabalho desses profissionais da saúde é realizado em conjunto e que só é possível ocorrer as transformações para melhorar a qualidade do serviço se houver participação de todos os trabalhadores. Outros autores ${ }^{1}$ discorrem sobre esse assunto ao afirmar que o modo de liderar fundamentado no poder e nas punições tem sido aceito como eficaz, porém em curto prazo. Em longo prazo, os integrantes da equipe tornam-se insatisfeitos e desmotivados com o trabalho tornando também a relação com o líder prejudicada.

$\mathrm{Na}$ rotina do profissional enfermeiro, o mesmo lida com situações imprevisíveis resultando em mudanças que requerem capacidade desse profissional para influenciar sua equipe a aceitar as transformações que contribuam para melhorar a assistência prestada ao cliente ${ }^{6}$. Há ainda que se considerar que o objetivo do enfermeiro líder é prestar assistência de enfermagem qualificada às pessoas que necessitam, sendo necessária a colaboração de todos os integrantes da equipe de enfermagem. Para alcançar essa assistência eficaz, o grupo precisa estar motivado a realizar sua tarefa com responsabilidade. O sucesso do trabalho depende de um ambiente saudável, sendo necessário valorizar as relações interpessoais contribuindo dessa forma para aumentar a produtividade e a eficiência no serviço.

Como líder, o enfermeiro deve conhecer as características de seu grupo, identificando talentos, dificuldades e facilidades de seus membros, moldando assim uma equipe comprometida com o trabalho ${ }^{7}$. Em outro estudo ${ }^{8}$ é abordado que para exercer a liderança o enfermeiro precisa 
ISSN 2179-6750

desenvolver certas características como: comprometimento, comunicação eficaz, capacidade de ouvir, competência, responsabilidade, visão, bom humor, capacidade de trabalhar em equipe, coerência, ética, flexibilidade e talento para estabelecer relações interpessoais saudáveis.

Em sua atuação o enfermeiro líder precisa focar no suprimento das necessidades dos clientes e das pessoas envolvidas no cuidado. Para isso, os autores reforçam a necessidade desses profissionais desenvolverem e aprimorarem habilidades de relacionamentos interpessoais ${ }^{9}$. Não se desenvolve a habilidade de liderar em seu potencial em cursos que duram duas semanas nem mesmo por meio de quatro anos de graduação. Segundo os autores, esses meios podem auxiliar, porém as competências mais complexas vão surgindo gradativamente podendo levar décadas. Por esse motivo, torna-se importante a permanência do aprendizado durante toda a vida profissional ${ }^{5}$.

A continuidade do aprendizado em liderança requer dos profissionais iniciativas em assumir riscos, saindo da rotina e experimentando ideias diferentes refletindo sobre as experiências para assim aprenderem continuamente. Esse processo de aprendizagem requer ainda integração de conhecimento, sempre considerando que em qualquer momento pode-se aprender com o outro 5 .

O problema do estudo se deu por meio da seguinte questão norteadora: Quais os desafios do exercício da liderança na prática do enfermeiro? Sendo assim, objetivou-se identificar os desafios do exercício da liderança na prática do enfermeiro por meio de uma revisão integrativa da literatura.

\section{Método}

Trata-se de uma revisão integrativa da literatura referente aos desafios encontrados pelos profissionais enfermeiros no exercício da liderança.

A revisão integrativa é a abordagem metodológica que permite a inclusão de estudos experimentais e não experimentais para uma compreensão completa do fenômeno analisado. A mesma é desenvolvida em etapas, sendo: formulação do problema, busca de dados na literatura, coleta dos dados, análise crítica dos estudos incluídos, discussão dos resultados e apresentação da revisão de literatura ${ }^{10,11}$.

Definição do problema; busca dos estudos; critérios de inclusão; coleta de dados; avaliação crítica dos mesmos e por fim síntese dos dados.

A primeira etapa é a mais importante do trabalho. Ela define a pergunta norteadora e delimitam quais serão os estudos incluídos, os meios adotados para a identificação e as informações coletadas de cada estudo selecionado. A pergunta norteadora deve ser elaborada de forma clara, específica, relacionada a um raciocínio teórico. A segunda etapa está relacionada à fase anterior e deve ser realizada uma busca de estudos sobre o assunto de forma ampla e diversificada em base de 
dados 12

ISSN 2179-6750

Podem-se incluir todos os estudos encontrados ou realizar a seleção randomizada; se essas duas possibilidades não forem viáveis pela quantidade de trabalhos, devem-se expor os critérios de inclusão e exclusão dos artigos. Tais critérios devem ser realizados de acordo com a pergunta norteadora, considerando os participantes, a intervenção e os resultados de interesse. A etapa seguinte consiste em coletar os dados para extraí-los dos estudos selecionados levando em consideração os critérios de inclusão e exclusão definidos anteriormente ${ }^{11}$.

A quarta etapa consiste na análise crítica dos estudos incluídos, exigindo uma abordagem organizada de forma a extrair as características relevantes de cada estudo e ajudar a determinar a funcionalidade prática do mesmo. Na quinta etapa, discutem-se os resultados partindo da interpretação e síntese dos mesmos, realizando uma comparação dos dados evidenciados na análise dos artigos com o referencial teórico ${ }^{11}$. A última etapa consiste na apresentação da revisão, devendo esta ser clara e completa para permitir a avaliação crítica dos resultados ${ }^{13}$. As formas de visualização podem ser expostas em tabelas, gráficos ou quadros, possibilitando assim a comparação entre todos os artigos selecionados, a identificação de padrões e diferenças ${ }^{14}$.

Para o levantamento literário, realizou-se a busca de publicações científicas brasileiras no banco de dados da Biblioteca Virtual em Saúde (BVS) e através desse banco de dados, teve-se acesso às bases de dados da Literatura Latino-Americana e do Caribe em Ciências da Saúde (LILACS) e BDENF, sendo utilizados os seguintes descritores: Liderança and Equipe de Enfermagem and Recursos Humanos de Enfermagem.

A população deste estudo constou de publicações indexadas nos referidos bancos de dados, no período de 2000 a 2012. Foram encontradas 477 publicações, sendo 276 indexadas na base de dados LILACS e 201 indexados no BDENF. Os critérios de inclusão consistiram em: periódicos indexados e publicados em revistas nacionais no período de 2000 a 2012, escritos em língua portuguesa, relacionados ao tema. Foram excluídas as publicações que não disponibilizaram o texto completo. A amostra final do estudo foi constituída de 11 publicações, sendo que oito foram indexadas na base de dados BDENF e três publicações na base de dados LILACS, considerando que todas estavam em língua portuguesa.

A busca foi realizada nos meses de março a abril de 2013. Para a coleta de dados, confeccionou-se uma tabela composta por oito variáveis para garantir a transcrição dos aspectos mais importantes do periódico: título, autor(es), ano, periódico, objetivo, métodos, resultados e conclusão. As informações obtidas dos artigos foram organizadas em tabela para serem comparadas e analisadas entre si, proporcionando conhecer nitidamente a produção científica relacionada aos 
ISSN 2179-6750

desafios encontrados pelos enfermeiros no exercício da liderança. As publicações selecionadas após análise foram sintetizadas e transcritas na tabela de acordo as variáveis analisadas. O presente estudo foi delineado obedecendo às etapas metodológicas acima descritas: Definição do problema; busca dos estudos; critérios de inclusão; coleta de dados; avaliação crítica dos mesmos e por fim síntese dos dados.

\section{Resultados}

A presente revisão integrativa foi construída a partir de artigos indexados nos bancos de dados da Biblioteca Virtual em Saúde (BVS) sendo provenientes das bases de dados: BDENF e LILACS. Para realização da pesquisa foi utilizado o seguinte descritor: Liderança and Equipe de Enfermagem and Recursos Humanos de Enfermagem, perfazendo um total de 477 artigos disponíveis na íntegra, distribuídos na tabela a seguir:

Tabela 1. Distribuição dos artigos segundo o descritor utilizado e as bases de dados LILACS e BDENF. Montes Claros, 2013.

\begin{tabular}{|c|c|c|c|c|}
\hline Base de dados & Descritor utilizado & Artigos encontrados & $\begin{array}{l}\text { Artigos } \\
\text { excluídos }\end{array}$ & Artigos selecionados \\
\hline LILACS & \multirow{2}{*}{$\begin{array}{c}\text { Liderança and Equipe } \\
\text { de Enfermagem and } \\
\text { Recursos Humanos de } \\
\text { Enfermagem }\end{array}$} & 276 & 273 & $03(27,3 \%)$ \\
\hline BDENF & & 201 & 193 & $08(72,7 \%)$ \\
\hline Total & & 477 & 466 & $11(100 \%)$ \\
\hline
\end{tabular}

A tabela 1 mostra que se recuperou um maior número de publicações na base de dados BDENF (72,7\% dos artigos), seguido pelo LILACS (27,3\% dos artigos). Excluiu-se 466 estudos, devido ao fato dos mesmos não atenderem aos critérios de inclusão. Em suma, foram incluídos $73 \%$ dos artigos da base de dados da BDENF, 27\% na base de dados do LILACS.

De acordo com a data de publicação dos estudos selecionados, houve maior publicação no ano de 2009, perfazendo um total de $27 \%$ de publicações, seguidas pelo ano de 2003 e 2010 com $18 \%$ de publicação cada. Quanto à metodologia das publicações utilizadas pelos autores dos estudos selecionados $81 \%$ constituíram de pesquisa qualitativa e $18 \%$ de pesquisa quanti-qualitativa. Verificou-se a maior quantidade de trabalhos publicados pelos periódicos: Revista Brasileira de Enfermagem e Revista Latino-Americana de Enfermagem, representando $18 \%$ de publicação em cada revista, as demais obtiveram um menor número de publicações, representando $9 \%$, cada periódico. A presente tabela nos mostra que o maior número de estudos foi desenvolvido em Hospitais Gerais, correspondendo a $64 \%$.

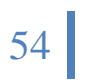


ISSN 2179-6750

Tabela 2. Artigos selecionados, segundo as variáveis utilizadas para avaliação. Montes claros (MG), 2013.

\begin{tabular}{|c|c|c|c|c|c|c|c|}
\hline Título & Autor & Ano & Periódico & Objetivo & Metodologia & Resultados & Conclusão \\
\hline $\begin{array}{l}\text { Aprendizagem da } \\
\text { Liderança: opinião } \\
\text { de Enfermeiros } \\
\text { sobre a Formação } \\
\text { Acadêmica. }\end{array}$ & $\begin{array}{l}\text { Simões; } \\
\text { Fávero }^{(15)}\end{array}$ & 2000 & $\begin{array}{l}\text { Rev Latino- } \\
\text { am Enferm }\end{array}$ & $\begin{array}{l}\text { Conhecer a opinião dos } \\
\text { enfermeiros sobre o preparo } \\
\text { realizado durante o curso de } \\
\text { graduação para liderarem a } \\
\text { equipe de enfermagem. }\end{array}$ & Pesquisa qualitativa & $\begin{array}{l}\text { Foram agrupados nas categorias: } \\
\text { Satisfatório e Insatisfatório. }\end{array}$ & $\begin{array}{l}\text { Evidenciou-se que existe } \\
\text { insatisfação por parte da } \\
\text { maioria dos profissionais } \\
\text { entrevistados em relação ao } \\
\text { preparo acadêmico para o } \\
\text { exercício da liderança. }\end{array}$ \\
\hline $\begin{array}{c}\text { O desafio da } \\
\text { liderança para o } \\
\text { enfermeiro. }\end{array}$ & $\begin{array}{l}\text { Simões; } \\
\text { Fávero }^{(16)}\end{array}$ & 2003 & $\begin{array}{l}\text { Rev Latino- } \\
\text { am Enferm }\end{array}$ & $\begin{array}{l}\text { Conhecer a opinião do } \\
\text { enfermeiro sobre a } \\
\text { possibilidade de tornar-se } \\
\text { líder, } \\
\text { características e habilidades } \\
\text { de um líder eficaz e } \\
\text { apresentar pontos fortes e } \\
\text { fracos relacionados ao } \\
\text { desempenho da liderança, } \\
\text { segundo a auto-avaliação } \\
\text { dos enfermeiros. }\end{array}$ & Pesquisa qualitativa & $\begin{array}{l}\text { Evidenciaram que a maioria dos } \\
\text { enfermeiros entrevistados concorda } \\
\text { que seja possível tornar-se líder; } \\
\text { credibilidade, comunicabilidade e } \\
\text { conhecimentos foram } \\
\text { características destacadas em um } \\
\text { líder; ter bom relacionamento, } \\
\text { envolvimento e segurança foram } \\
\text { atitudes responsáveis pelo sucesso } \\
\text { do enfermeiro nas experiências de } \\
\text { liderança, caracterizando os pontos } \\
\text { fortes, enquanto que insegurança e } \\
\text { comunicação ineficaz } \\
\text { representaram os pontos fracos. }\end{array}$ & $\begin{array}{l}\text { Concluiu-se que existem } \\
\text { perspectivas para o enfermeiro } \\
\text { melhorar seu desempenho na } \\
\text { liderança, desde que haja } \\
\text { mudanças no comportamento, } \\
\text { aquisição de conhecimentos e } \\
\text { desenvolvimento de } \\
\text { habilidades específicas. }\end{array}$ \\
\hline $\begin{array}{l}\text { Aprendizagem da } \\
\text { liderança; } \\
\text { contribuições do } \\
\text { internato em } \\
\text { enfermagem para } \\
\text { a formação do } \\
\text { estudante. }\end{array}$ & $\begin{array}{l}\text { Ramos; } \\
\text { Freitas; } \\
\text { Silva }\end{array}$ & 2011 & $\begin{array}{l}\text { Esc Anna } \\
\text { Nery Rev } \\
\text { Enferm }\end{array}$ & $\begin{array}{l}\text { Analisar o entendimento de } \\
\text { internos de Enfermagem } \\
\text { sobre liderança; verificar as } \\
\text { dificuldades encontradas } \\
\text { pelos acadêmicos em } \\
\text { desempenhar atividades de } \\
\text { liderança; e conhecer as } \\
\text { contribuições do internato } \\
\text { em Enfermagem para os } \\
\text { estudantes na construção da } \\
\text { competência em liderança. }\end{array}$ & $\begin{array}{c}\text { Pesquisa exploratória e } \\
\text { descritiva com } \\
\text { abordagem qualitativa. }\end{array}$ & $\begin{array}{l}\text { Os resultados foram expostos em } \\
\text { forma de categorias dos discursos. } \\
\text { As informações evidenciaram o } \\
\text { conhecimento possuído pelos } \\
\text { participantes acerca da liderança; a } \\
\text { importância desta aprendizagem na } \\
\text { formação dos enfermeiros; o } \\
\text { destaque de competências } \\
\text { essenciais para a atuação do } \\
\text { enfermeiro-líder, as dificuldades } \\
\text { encontradas nas atividades de } \\
\text { liderança durante a graduação e as } \\
\text { contribuições do internato no } \\
\text { último ano para a aprendizagem de }\end{array}$ & $\begin{array}{l}\text { Os entrevistados mostraram } \\
\text { ciência em relação à } \\
\text { complexidade da liderança } \\
\text { exigida pela profissão do } \\
\text { enfermeiro; em relação às } \\
\text { competências necessárias para } \\
\text { o exercício da liderança foi } \\
\text { destacada o conhecimento } \\
\text { técnico- cientifico, } \\
\text { responsabilidade, integridade, } \\
\text { respeito e caráter. As } \\
\text { dificuldades citadas foram o } \\
\text { relacionamento com a equipe, } \\
\text { pela adequação do interno na }\end{array}$ \\
\hline
\end{tabular}




\section{J Online} Enferm Bras.

Conhecer o significado de iderança atribuído pelos enfermeiros

\section{Pesquisa Qualitativa}

(2)

Liderança do

enfermeiro:

desafios da prática.

\section{Liderança \\ Transformacional \\ na Enfermagem.}

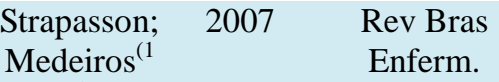 9)}

\section{da}

Verificar se os pressupostos presentes na prática de enfermeiros de um hospital de médio porte do interior do Rio Grande do Sul.
Foram agrupados nas categorias: Percepção do conceito de liderança, vantagens do exercício da liderança em enfermagem, escolha da função de liderança, percepção das dificuldades da função de liderança e realização dos objetivos do trabalho. líderes.

O cenário para os
profissionais de saúde, onde predomina uma liderança autocrática, é extremamente complexo e exige dos enfermeiros/ líderes

capacidade de reflexão para entender os problemas de cada membro da equipe de trabalho, para estabelecer formas de melhorar o moral e o ego de cada profissional que trabalha diretamente com o paciente.

Pesquisa Qualitativa

Emergiram cinco categorias: significado de liderança, enfermeiros reações diversa. habilidades essenciais para o Fica evidente a existência de exercício da liderança, exercício dificuldades em liderar no das habilidades de liderança no cotidiano de trabalho dos cotidiano dos enfermeiros, enfermeiros. Parecem estar participação da Organização no sem referência, faltando desenvolvimento da liderança e clareza sobre o que a resistência dos enfermeiros ao organização espera deles e processo de mudança.

vice-versa gerando insegurança no estilo de liderança a ser adotado.

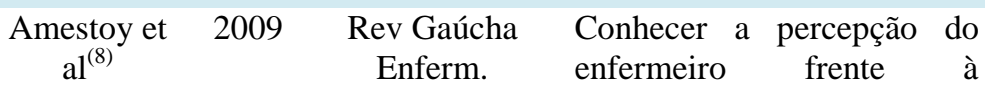
utilização da liderança como instrumento gerencial no seu processo de trabalho.

Pesquisa qualitativa

Obtiveram-se duas categorias: significados atribuídos à liderança e autoridade versus autoritarismo.

que, mesmo a

liderança oferecendo vantagens ao trabalho da enfermagem, ainda são grandes as dificuldades para compreendê-la, 


\begin{tabular}{|c|c|c|c|c|c|c|c|}
\hline $\begin{array}{l}\text { Características que } \\
\text { interferem na } \\
\text { construção do } \\
\text { enfermeiro- líder. }\end{array}$ & Amestoy $^{(6)}$ & 2009 & $\begin{array}{l}\text { Acta Paul } \\
\text { Enferm. }\end{array}$ & $\begin{array}{l}\text { Conhecer as características } \\
\text { que interferem na construção } \\
\text { do enfermeiro-líder. }\end{array}$ & Pesquisa Qualitativa. & $\begin{array}{l}\text { Os entrevistados afirmaram que o } \\
\text { líder pode ser construído, além de } \\
\text { concordarem que os enfermeiros } \\
\text { necessitam desenvolver algumas } \\
\text { características com o intuito de } \\
\text { contribuir para o desenvolvimento } \\
\text { da liderança. }\end{array}$ & $\begin{array}{l}\text { Concluiu-se que as } \\
\text { características principais que } \\
\text { devem ser cultivadas na } \\
\text { construção do enfermeiro líder } \\
\text { foram: comunicação, } \\
\text { conhecimento, } \\
\text { responsabilidade, bom senso e } \\
\text { autoconhecimento. }\end{array}$ \\
\hline $\begin{array}{l}\text { Liderança na } \\
\text { Enfermagem; } \\
\text { aprendizado na } \\
\text { graduação. }\end{array}$ & $\begin{array}{l}\text { Jabur; } \\
\text { Dusso; } \\
\text { Haro }^{(20)}\end{array}$ & 2009 & $\begin{array}{l}\text { Cuid Arte } \\
\text { Enferm }\end{array}$ & $\begin{array}{l}\text { Avaliar a percepção de } \\
\text { egressos de um curso de } \\
\text { graduação em enfermagem } \\
\text { de uma instituição de ensino } \\
\text { quanto ao conteúdo } \\
\text { programático de liderança } \\
\text { desenvolvido na graduação; } \\
\text { verificar se o conteúdo } \\
\text { favoreceu o aprendizado, } \\
\text { identificar se as habilidades } \\
\text { necessárias ao líder foram } \\
\text { desenvolvidas na graduação; } \\
\text { identificar as facilidades e } \\
\text { dificuldades dos egressos no } \\
\text { exercício da liderança e as } \\
\text { possíveis sugestões para } \\
\text { modificação do conteúdo } \\
\text { programático. }\end{array}$ & $\begin{array}{c}\text { Pesquisa Quanti- } \\
\text { qualitativa. }\end{array}$ & $\begin{array}{l}\text { A maioria } \begin{array}{c}\text { dos } \\
\text { considerou }\end{array} \text { o } \begin{array}{r}\text { conteúdo } \\
\text { programático } \\
\text { sobre liderança }\end{array} \\
\text { satisfatório e referiram que } \\
\text { favoreceu o aprendizado. As } \\
\text { habilidades apreendidas citadas } \\
\text { foram: relacionamento interpessoal, } \\
\text { comunicação, negociação e bom } \\
\text { senso. Alguns alegaram que essas } \\
\text { habilidades foram desenvolvidas } \\
\text { em parte na graduação, outros } \\
\text { disseram que nenhuma delas foram } \\
\text { aprendidas na academia. Relataram } \\
\text { como facilidades fundamentais para } \\
\text { o exercício da liderança: "saber } \\
\text { ouvir" e "negociação". Como } \\
\text { dificuldades citaram falta de } \\
\text { experiência, relacionamento com } \\
\text { funcionários mais antigos e não ser } \\
\text { autoritário. Foram apontadas como } \\
\text { sugestões: oferecer mais dinâmicas } \\
\text { e vivências, palestras, além de } \\
\text { aumentar a carga horária dessas } \\
\text { disciplinas. }\end{array}$ & $\begin{array}{l}\text { Concluiu-se que apesar do } \\
\text { ensino de liderança na } \\
\text { graduação ter favorecido o } \\
\text { aprendizado, este não foi } \\
\text { suficiente para que os egressos } \\
\text { do curso exercessem a } \\
\text { liderança em seus trabalhos de } \\
\text { forma segura. }\end{array}$ \\
\hline
\end{tabular}


ISSN 2179-6750

\begin{tabular}{|c|c|c|c|c|c|c|c|}
\hline $\begin{array}{l}\text { Liderança: um } \\
\text { desafio para o } \\
\text { enfermeiro recém- } \\
\text { formado. }\end{array}$ & $\begin{array}{c}\text { Vilela; } \\
\text { Souza }^{(21)}\end{array}$ & 2010 & $\begin{array}{l}\text { Rev Enferm } \\
\text { UERJ. }\end{array}$ & $\begin{array}{l}\text { Identificar os desafios que o } \\
\text { enfermeiro recém- formado } \\
\text { encontra para exercer a } \\
\text { função de liderança e as } \\
\text { estratégias adotadas. }\end{array}$ & $\begin{array}{l}\text { Pesquisa Quanti- } \\
\text { qualitativa }\end{array}$ & $\begin{array}{l}\text { Agrupou-se em três categorias: } \\
\text { atributos, desafios e estratégias } \\
\text { adotadas no exercício da liderança. }\end{array}$ & $\begin{array}{l}\text { Conclui-se que fatores } \\
\text { relacionados à insegurança, às } \\
\text { dificuldades de comunicação, } \\
\text { de pouco entrosamento com } \\
\text { os demais membros da equipe, } \\
\text { de tomada de decisões e de } \\
\text { destreza na realização de } \\
\text { procedimentos constituem } \\
\text { desafios para o exercício da } \\
\text { liderança. }\end{array}$ \\
\hline $\begin{array}{c}\text { Processo de } \\
\text { formação dos } \\
\text { enfermeiros líderes }\end{array}$ & $\begin{array}{l}\text { Amestoy et } \\
\text { al. }^{(22)}\end{array}$ & 2010 & $\begin{array}{l}\text { Rev Bras } \\
\text { Enferm }\end{array}$ & $\begin{array}{l}\text { Conhecer o papel de uma } \\
\text { instituição de ensino } \\
\text { superior e hospitalar na } \\
\text { formação e educação } \\
\text { permanente de enfermeiros- } \\
\text { líderes. }\end{array}$ & Pesquisa Qualitativa. & $\begin{array}{l}\text { Emergiram-se duas categorias: } \\
\text { papel da instituição de ensino } \\
\text { superior na formação de } \\
\text { enfermeiros-líderes e papel } \\
\text { instituição hospitalar na educação } \\
\text { permanente de enfermeiros-líderes. }\end{array}$ & $\begin{array}{l}\text { Concluiu-se que r as } \\
\text { enfermeiras estão pouco } \\
\text { instrumentalizadas para } \\
\text { exercer a liderança enquanto } \\
\text { competência profissional. }\end{array}$ \\
\hline $\begin{array}{l}\text { O enfermeiro e a } \\
\text { estratégia saúde da } \\
\text { família: desafios } \\
\text { em coordenar a } \\
\text { equipe } \\
\text { multiprofissional }\end{array}$ & $\begin{array}{l}\text { Spagnuolo; } \\
\text { Juliani }^{(23)}\end{array}$ & 2012 & $\begin{array}{l}\text { Ciênc Cuid } \\
\text { Saúde }\end{array}$ & $\begin{array}{l}\text { Compreender o papel do } \\
\text { enfermeiro no exercício da } \\
\text { coordenação de uma equipe } \\
\text { na Estratégia Saúde da } \\
\text { Família, em relação as } \\
\text { competências e habilidades } \\
\text { praticadas e desenvolvidas } \\
\text { no seu cotidiano de trabalho } \\
\text { e as dificuldades em exercer } \\
\text { essa função de acordo com a } \\
\text { percepção } \\
\text { profissionais. }\end{array}$ & Pesquisa Qualitativa & $\begin{array}{l}\text { Evidenciou-se cinco categorias: o } \\
\text { contexto da coordenação de equipes } \\
\text { multiprofissionais na ESF, fatores } \\
\text { intervenientes no cotidiano do } \\
\text { trabalho na ESF, conflitos vividos } \\
\text { na interface entre o trabalho em } \\
\text { equipe e a coordenação central na } \\
\text { ESF, dificuldades da população } \\
\text { diante do novo modelo de atenção } \\
\text { coordenado pelo enfermeiro e a } \\
\text { competência sentida no exercício da } \\
\text { liderança em coordenar equipes } \\
\text { multiprofissionais. }\end{array}$ & $\begin{array}{l}\text { Concluiu-se que as } \\
\text { enfermeiras encontram-se } \\
\text { despreparadas para coordenar } \\
\text { a ESF bem como existe uma } \\
\text { sobrecarga e sobreposição de } \\
\text { tarefas a falta de capacitação } \\
\text { como fatores que dificultam } \\
\text { essa prática. O estudo mostrou } \\
\text { a necessidade de discutir a } \\
\text { formação dos enfermeiros no } \\
\text { âmbito acadêmico e prepará- } \\
\text { los para o enfrentamento dos } \\
\text { desafios colocados à } \\
\text { coordenação de uma equipe. }\end{array}$ \\
\hline
\end{tabular}


Tabela 3. Distribuição da amostra segundo o ano de publicação, o periódico e o cenário de estudo do artigo. Montes Claros (MG), 2013.

\begin{tabular}{clcc}
\hline Variável & \multicolumn{1}{c}{ Descrição } & n=11 & $\%$ \\
& 2000 & 01 & 9,1 \\
& 2003 & 02 & 18,1 \\
& 2004 & 01 & 9,1 \\
\multirow{3}{*}{ Ano de publicação } & 2007 & 01 & 9,1 \\
& 2009 & 03 & 27,4 \\
& 2010 & 02 & 18,1 \\
& 2012 & 01 & 9,1 \\
\hline & Rev Latino-am Enferm & 02 & 18,15 \\
& Rev Bras Enferm & 02 & 18,15 \\
& Rev Esc Enferm USP & 01 & 9,1 \\
& Ciênc Cuid Saúde & 01 & 9,1 \\
& Cuid Arte Enferm & 01 & 9,1 \\
& Acta Paul Enferm & 01 & 9,1 \\
& J Online Enferm Bras & 01 & 9,1 \\
& Rev Gaúcha Enferm & 01 & 9,1 \\
& Rev Enferm UERJ & 01 & 9,1 \\
\hline & Hospital Geral & 07 & 63,6 \\
& Cursos de graduação em Enfermagem & 03 & 27,3 \\
& Estratégias Saúde da Família & 01 & 9,1 \\
\hline \multirow{2}{*}{ Cenário } & & &
\end{tabular}

Fonte: Pesquisa em base de dados eletrônicos da Biblioteca Virtual de Saúde (BVS, 2013)

\section{Discussão}

A prática da $\mathrm{Na}$ presente pesquisa foram encontrados 477 artigos, sendo que apenas 11 artigos foram selecionados considerando os critérios de inclusão, sendo considerados os artigos em português disponíveis na íntegra. Portanto, dos artigos selecionados $100 \%$ estavam disponíveis na íntegra em língua portuguesa. Houve maior publicação no ano de 2009 perfazendo um total de $27 \%$ de publicações.

No que tange à metodologia das publicações utilizadas pelos autores dos estudos selecionados, predominou o qualitativo representado $81 \%$. Verificou-se que a maior quantidade dos artigos foram publicados pelos periódicos: Revista Brasileira de Enfermagem e Revista Latinoamericana de Enfermagem, ambas compreendendo 18\% da publicações. O maior número de estudos foi desenvolvido em Hospital Geral, correspondendo a 64\%. Após a escolha, leitura e análise dos estudos selecionados, possibilitaram-se delimitar variáveis relevantes para a reflexão a respeito dos desafios encontrados pelos enfermeiros no exercício da liderança.

A capacidade de liderar é uma das principais competências a ser adquirida pelo profissional enfermeiro, uma vez que o trabalho em equipe exige dos enfermeiros aptidão para assumir posições de liderança ${ }^{19}$. Observa-se, no entanto deficiências pelos enfermeiros em exercer o papel de líder. Os mesmos autores colocam que existem sentimentos como insegurança quanto à tomada de decisões pelos enfermeiros devido à ausência de clareza sobre o que a instituição espera dos 
ISSN 2179-6750

mesmos e do que esses profissionais buscam na instituição.

Apontam-se também dificuldades no relacionamento em equipe e que o desempenho da função de líder encontra-se inúmeras vezes permeadas por dificuldades decorrentes da inabilidade em lidar com situações grupais, da falta de conhecimentos profissionais e da incapacidade de manter uma comunicação eficaz ${ }^{16}$. Essa questão é afirmada também por outros autores ${ }^{21}$ que destacam como dificuldades no exercício da liderança pelos enfermeiros o relacionamento interpessoal além da aceitação por parte da equipe, profissionais desatualizados e fatores relacionados à inexperiência quando se trata de enfermeiros recém- formados. Esses autores afirmam que a escassez de recursos também é um fator que dificulta a eficiência da liderança, fato que é corroborado em outro estudo ${ }^{18}$ ao afirmar que para se desenvolver um trabalho eficaz e ter bons resultados são necessários dois conjuntos de recursos: humanos e financeiros. Como nas instituições públicas esses recursos são escassos, é preciso ter o máximo de aproveitamento para se alcançar os objetivos propostos. Problemas aparentemente intransponíveis, falta de recursos e desmotivação, têm sido e continuarão sendo questões enfrentadas pelos enfermeiros líderes. Dessa forma a escassez de pessoal de enfermagem para a assistência direta aos pacientes e os baixos salários oferecidos tornam o trabalho do líder uma missão quase impossível de se realizar. Considera-se ainda que a dificuldade na comunicação com a equipe e a falta de habilidade técnica são fatores que interferem no exercício eficiente da liderança pelo enfermeiro.

Os enfermeiros como coordenadores de equipe deparam também com o desafio de lidar com a equipe multiprofissional na atenção básica em saúde. Esses profissionais encontram após sua formação uma equipe diferente da que foram preparados para coordenar pelo curso de graduação. Demonstram dessa forma dificuldade em se auto perceber nesse processo de trabalho, apontando dificuldades em perceberem a dimensão do trabalho em uma equipe multiprofissional. $O$ profissional enfermeiro geralmente se sente despreparado para atuar na coordenação dessa equipe ${ }^{24}$. A abordagem do tema muitas vezes gera inquietação por parte dos enfermeiros demonstrando ser um assunto complicado e difícil de ser definido ${ }^{19}$.

Cinco enfermeiros de um estudo afirmam não acreditar que seja possível tornar-se líder, alegando que a liderança depende de características pessoais natas, de possuir dom, ou seja, concordam que um líder já nasce líder ${ }^{16}$. Quatro enfermeiros de outro estudo compreendem a liderança como algo impossível de ser aprendido, definindo-a como algo nato na pessoa, acreditando em um potencial inicial que, se desenvolvido, pode fazer com que o indivíduo capacitese para a liderança ${ }^{19}$. Quanto às habilidades essenciais para o exercício da liderança, pode-se inferir que os entrevistados confundem conhecimento, rotinas e técnicas com liderança. Acreditam que o 
ISSN 2179-6750

conhecimento teórico-prático e todos os processos e rotinas de enfermagem são habilidades essenciais para o exercício da liderança.

O conhecimento é necessário nas práticas de saúde. No entanto, ele isolado não é suficiente para que os profissionais trabalhem com as pessoas, desenvolvam relacionamentos saudáveis e compreendem a realidade do seu ambiente de trabalho na dimensão psicossocial para intervir de forma correta e alcançar os objetivos almejados ${ }^{19}$.

São grandes as dificuldades de compreensão por parte de muitos enfermeiros sobre o que é a liderança e consequentemente coexiste a dificuldade em praticá-la ${ }^{3,8}$. O exercício da liderança está relacionado à disposição do enfermeiro em querer aprender a desenvolver as habilidades de liderança. São consideradas habilidades essenciais de um líder a comunicação, a educação, o conhecimento técnico e científico e a corresponsabilidade ${ }^{21}$. A comunicação é considerada uma das principais virtudes de um líder uma vez que sem ela torna-se difícil o mesmo influenciar seus colaboradores. É a principal ferramenta que possibilita o relacionamento, pressupondo uma interação entre as pessoas, troca ou partilha de opiniões, informações e, mesmo, a expressão de sentimentos e emoções.

A comunicação não se restringe ao que se diz, mas engloba a forma como as palavras são ditas. A chave da comunicação eficiente caracteriza-se pela simplicidade. Se o líder pretende motivar seus seguidores deve tornar sua mensagem simples e de fácil compreensão ${ }^{3,8}$. A honestidade, competência, olhar para diante e inspiração são características admiradas pelos seguidores em seus líderes. Tais atributos podem ser resumidos em um único termo: credibilidade. O que mais as pessoas esperam de um líder é que ele desperte confiança, que seja digno de crédito, demonstrando coerência com a filosofia da instituição e congruência em suas ideias, discurso e ações; a lealdade e o comprometimento dos seguidores podem depender da credibilidade percebida ${ }^{16}$. Acredita-se que o exemplo positivo do líder poderá fortalecer o respeito entre os membros do grupo, além de influenciar sua equipe a desenvolver estas mesmas características ${ }^{3,8}$.

Estudos contemporâneos sobre liderança afirmam que líderes podem ser formados, independentemente das características pessoais que possuam. Com essa visão, pode-se perceber o papel desafiador e a responsabilidade que as instituições de ensino têm em formar e lançar no mercado de trabalho, profissionais devidamente preparados para assumir a função de liderar a equipe de enfermagem. Há um número significativo de enfermeiros insatisfeitos com o ensino, despreparados e inseguros quanto ao desempenho da liderança. Sabe-se que a prática profissional é frutífera e enriquece sobremaneira os conhecimentos teóricos, porém, cabe à escola, enquanto órgão formador, proporcionar condições de ensino que subsidiem e torne esse processo menos árduo para 
ISSN 2179-6750

o enfermeiro em seu cotidiano profissional. Um número menor de profissionais enfermeiros sentese satisfeitos com o ensino na graduação sobre liderança o que permite inferir que houve por parte dos cursos de graduação, uma preocupação com o repasse de conteúdos teóricos a respeito de liderança, fazendo com que os entrevistados sintam-se preparados apenas "teoricamente" para liderar a equipe de enfermagem. É necessário, no entanto, que as instituições aliem teoria à prática 15

Acredita-se que a formação do enfermeiro é permeada por diversas habilidades e competências, as quais vão sendo construídas ao longo do processo de formação acadêmica que inclui uma multiplicidade de conhecimentos e práticas, bem como a associação da teoria e prática, ou seja, a práxis em saúde ${ }^{15,17,23}$. Esse contexto exige que a postura dos educadores e outros profissionais com quem os estudantes interagem, ao longo das vivências acadêmicas, os estimulem a desenvolver as competências necessárias para tornarem-se líderes.

Estudos a respeito do ensino de enfermagem revelaram que a formação tem priorizado o aprendizado de procedimentos técnicos ${ }^{15,17}$. Verifica-se também que os conteúdos teóricos têm sido apresentados na forma de aulas exaustivas sem a devida relevância do seu significado real e, desarticulados entre si, não oferecendo o retorno desejado ao aluno. Este tipo de ensino pode explicar, pelo menos em parte a dificuldade no exercício da liderança, tendo em vista que o mesmo, quando descontextualizado da prática e da realidade laboral, não instrumentaliza o futuro profissional para ser líder da equipe, uma vez que a liderança exige tomada de decisão a partir do vivido.

Durante a graduação, contata-se que alguns estudantes preocupam-se, excessivamente, em realizar atividades técnicas. Assim, é possível visualizar o tecnicismo na formação, a desvalorização de aspectos gerenciais, como a liderança, que muitas vezes, é lembrada quando o enfermeiro já está inserido na prática profissional e necessita solucionar conflitos, além de coordenar uma equipe, que em geral, é constituída por profissionais com mais idade e experiência ${ }^{3,8}$. Após a conclusão do curso, no exercício profissional, especialmente na coordenação da equipe de enfermagem, emergem situações, as quais exigem, não apenas o conhecimento teórico, mas a aplicação imediata dos conceitos de liderança ${ }^{20}$.

\section{Considerações Finais}

A análise dos dados coletados relacionados aos desafios encontrados pelos enfermeiros no exercício da liderança permite concluir que esses profissionais encontram-se despreparados para exercer a função de líder. Pode-se inferir que essa situação é consequência de um ensino na 62 
ISSN 2179-6750

graduação deficiente sobre o tema. Este deve ser trabalhado tanto na teoria quanto na prática, pois somente ao vivenciar situações com a equipe é que se pode realmente aprender e aperfeiçoar as habilidades essenciais para o exercício da liderança. Percebe-se que a prática tem sido pouco vivenciada pelos graduandos que ao depararem com a realidade após a formação não sabem como agir eficientemente nas diversas situações apresentadas.

Depreende-se também a inabilidade em exercer a liderança e em procurar aprendê-la uma vez que alguns a considera como uma característica nata do ser. Esse conhecimento equivocado da liderança permite inferir o déficit do ensino teórico na graduação.

As escolas de enfermagem devem, portanto investir na formação de profissionais preparados para lidar com equipes exercendo a liderança de forma eficiente e garantindo a qualidade do cuidado prestado ao cliente. Torna-se necessário refletir sobre a responsabilidade que as instituições de ensino têm em formar e lançar no mercado de trabalho profissional competente para desempenhar a função de líder influenciando e motivando seus membros a buscar sempre a qualidade no cuidado dirigido ao cliente.

Por fim este trabalho não visa esgotar a discussão sobre o assunto, mas conduzir a uma reflexão a luz da literatura sobre os desafios encontrados pelos profissionais enfermeiros no exercício da liderança para que os mesmos possam ser sanados por meio de um ensino eficiente na graduação que associe teoria e prática além de ser aprimorado por meio da educação permanente nos hospitais.

\section{Referências}

1. Souza LB, Barroso MGT. Reflexão sobre o cuidado como essência da liderança em enfermagem. Esc Anna Nery. 2009;13(1):181-7. doi: http://dx.doi.org/10.1590/S141481452009000100025

2. Gelbecke FL, Souza LA, Dal Sasso GM, Nascimento E, Bulb MBC. Liderança em ambientes de cuidados críticos: reflexões e desafios à enfermagem brasileira. Rev Bras Enferm. 2009;62(1):136-9. doi: http://dx.doi.org/10.1590/S0034-71672009000100021

3. Amestoy SC, Cestari ME, Thofehrn MB, Milbrath VM, Porto AR. Significados atribuídos ao líder na visão de enfermeiras. Cienc Cuid Saúde. 2009;8(4):579-85. doi: http://dx.doi.org/10.4025/cienccuidsaude.v8i4.9677

4. Silva LF, Cunha ICKO. Liderança em enfermagem: conceitos, evolução e dificuldade dos enfermeiros. Rev Enferm UNISA. 2005;6:58-63. Disponível em: http://www.unisa.br/graduacao/biologicas/enfer/revista/arquivos/2005-10.pdf 
ISSN 2179-6750

5. Gaidzinski RR, Peres HHC, Fernandes MFP. Liderança: aprendizado contínuo no gerenciamento em enfermagem. Rev Bras Enferm. 2004;57(4):464-6. doi: http://dx.doi.org/10.1590/S0034-71672004000400015

6. Amestoy SC, Cestari ME, Thofehrn MB, Milbrath VM. Características que interferem na construção do enfermeiro líder. Acta Paul Enferm. 2009;22(5):673-8. doi: http://dx.doi.org/10.1590/S0103-21002009000500012

7. Neves VR, Sanna MC. Ensino da liderança em enfermagem: um estudo bibliométrico. Acta Paul Enferm. 2012;25(2):308-13. doi: http://dx.doi.org/10.1590/S0103-21002012000200024

8. Amestoy SC, Cestari ME, Thofehrn MB, Backes VMS, Milbrath VM, Trindade LL. As percepções dos enfermeiros acerca da liderança. Rev Gaúcha Enferm. 2009;30(4):617-24. doi: http://dx.doi.org/10.1590/S1983-14472009000400006

9. Moreira MC, Silva SCSB. Práticas de liderança adotadas por enfermeiros no serviço noturno. Rev Enferm UERJ. 2007;15(2):183-9. Disponível em: http://www.facenf.uerj.br/v15n2/v15n2a05.pdf

10. Gil AC. Como elaborar projetos de pesquisa. 4 ed. São Paulo: Atlas, 2002.

11. Souza MT, Silva MD, Carvalho R. Revisão integrativa: o que é e como fazer. Einstein. 2010; 8(1):102-6. doi: http://dx.doi.org/10.1590/s1679-45082010rw1134

12. Galvão CM, Sawada NO, Trevizan MA. Revisão sistemática: recurso que proporciona a incorporação das evidências na prática de enfermagem. Rev Latino-Am Enferm. 2004;12(3):549-56. doi: http://dx.doi.org/10.1590/S0104-11692004000300014

13. Silveira RCCP, Galvão CM. O cuidado de enfermagem e o cateter de Hickman: a busca de evidências. Acta Paul Enferm. 2005;18(3):276-84. doi: http://dx.doi.org/10.1590/S010321002005000300008

14. Freitas CBD, Novaes HMD. Lideranças de comitês de ética em pesquisa no Brasil: perfil e atuação. Rev Bioet. 2010;18(1):185-200. Disponível em: http://www.revistabioetica.cfm.org.br/index.php/revista_bioetica/article/view/544/530

15. Simões ALA, Fávero N. Aprendizagem da liderança: opinião de enfermeiros sobre a formação acadêmica. Rev Latino-Am Enferm. 2000;8(3):91-6. doi: http://dx.doi.org/10.1590/S0104-11692000000300013

16. Simões ALA, Fávero N. O desafio da liderança para o enfermeiro. Rev Latino-Am Enferm. 2003;11(5):567-73. doi: http://dx.doi.org/10.1590/S0104-11692003000500002

17. Ramos VM, Freitas CASL, Silva MJ. Aprendizagem da liderança: contribuição do internato em enfermagem para a formação do estudante. Esc Anna Nery. 2011;15(1):157-61. doi: 
ISSN 2179-6750

http://dx.doi.org/10.1590/S1414-81452011000100022

18. Santos SR, Moreira RC. Liderança do enfermeiro: desafios da prática. Online Braz J Nurs. 2004;3(3):1-7. Disponível em: http://www.nepae.uff.br//siteantigo/objn303santosetal.htm

19. Strapasson MR, Medeiros CRG. Liderança transformacional na enfermagem. Rev Bras Enferm. 2009;62(2):228-33. doi: http://dx.doi.org/10.1590/S0034-71672009000200009

20. Jabur MRL, Dusso MS, Haro MC. Liderança na enfermagem: aprendizado na graduação. Cuid Arte Enferm. 2009;3(2):129-33. Disponível em: http://www.fundacaopadrealbino.org.br/facfipa/ner/pdf/ed05enfpsite.pdf

21. Vilela PF, Souza AC. Liderança: um desafio para o enfermeiro recém-formado. Rev Enferm UERJ. 2010;18(4):591-7. Disponível em: http://www.facenf.uerj.br/v18n4/v18n4a15.pdf

22. Amestoy SC, Cestari ME, Thofehrn MB, Milbrath VM, Trindade LL, Backes VMS. Processo de formação dos enfermeiros líderes. Rev Bras Enferm. 2010;63(3):940-5. doi: http://dx.doi.org/10.1590/S0034-71672010000600011

23. Spagnuolo RS, Juliani CMCM, Spiri WC, Bocchi SCM, Martins STF. O enfermeiro e a estratégia saúde da família: desafios em coordenar a equipe multiprofissional. Cienc Cuid Saúde. 2012;11(2):226-34. doi: http://dx.doi.org/10.4025/cienccuidsaude.v11i2.10445

24. Martins JAC, Mazzo A, Baptista RCN, Coutinho VRD, Godoy S, Mendes IAC et al. A experiência clínica simulada no ensino de enfermagem: retrospectiva histórica. Acta Paul Enferm. 2012;25(4):619-25. doi: http://dx.doi.org/10.1590/S0103-21002012000400022 